\title{
Variability in HOMA-IR, Lipoprotein Profile and Selected Hormones in Young Active Men
}

\author{
Anna Keska, ${ }^{1}$ Grazyna Lutoslawska, ${ }^{1}$ Anna Czajkowska, ${ }^{2}$ \\ Joanna Tkaczyk, ${ }^{1}$ and Krzysztof Mazurek ${ }^{3}$ \\ ${ }^{1}$ Department of Biochemistry and Biology, Józef Pilsudski University of Physical Education, P.O. Box 55, 01-968 Warsaw 45, Poland \\ ${ }^{2}$ Department of Physiology, Józef Pilsudski University of Physical Education, P.O. Box 55, 01-968 Warsaw 45, Poland \\ ${ }^{3}$ Department of Sports Medicine, Józef Pilsudski University of Physical Education, P.O. Box 55, 01-968 Warsaw 45, Poland
}

Correspondence should be addressed to Anna Keska; anna.keska@awf.edu.pl

Received 30 August 2013; Accepted 25 September 2013

Academic Editors: C. C. Juhlin and G. B. Melis

Copyright (C) 2013 Anna Keska et al. This is an open access article distributed under the Creative Commons Attribution License, which permits unrestricted use, distribution, and reproduction in any medium, provided the original work is properly cited.

\begin{abstract}
Resistance to insulin actions is contributing to many metabolic disturbances. Such factors as age, sex, nutrition, body fat, and physical activity determine body insulin resistance. Present study attempted to asses insulin resistance and its metabolic effects with respect to energy intake in young, lean, and active men. A total of 87 men aged 18-23 participated in the study. Plasma levels of glucose, insulin, lipoproteins, cortisol, and TSH were determined. Insulin resistance was expressed as Homeostasis Model Assessment for Insulin Resistance (HOMA-IR) and calculated using homeostatic model. The median value of HOMA-IR (1.344) was used to divide subjects into two groups. Men did not differ in anthropometric parameters, daily physical activity, and plasma TSH and cortisol levels. However, in men with higher HOMA-IR significantly lower daily energy intake was observed concomitantly with higher TG, TC, and HDL-C concentrations in plasma versus their counterparts with lower HOMA-IR. Exclusively in subjects with higher HOMA-IR significant and positive correlation was noted between HOMA-IR and TC and LDL-C. We concluded that despite a normal body weight and physical activity, a subset of young men displayed unfavorable changes in insulin sensitivity and lipid profile, probably due to insufficient energy intake.
\end{abstract}

\section{Introduction}

Several studies have demonstrated that insulin is involved in the regulation of peripheral carbohydrate, lipid, and protein metabolism as well in the central regulation of energy homeostasis $[1,2]$. It suppresses hepatic glucose and triglyceride production, inhibits adipose tissue lipolysis, whole body, and muscle proteolysis, and stimulates glucose uptake in muscles [3].

In consequence, resistance to insulin (IR) is contributing to the development of many metabolic disturbances. It was shown that resistance to insulin-stimulated glucose uptake, especially in adipose tissue, liver, and muscle brings about type 2 diabetes, one of the most common chronic diseases $[4,5]$. Insulin resistance also interferes with lipid metabolism leading to atherosclerosis, hypertension, and cardiovascular disease (CVD) [6].
It is well documented that insulin sensitivity varies due to many factors, including age, sex, nutrition, and physical activity [7]. Insulin sensitivity decreases with age due to increasing body fat stores, especially in the abdominal region [8].

Women appeared to be more sensitive to insulin action both in the liver and in muscles. Dissimilarities in insulin sensitivity between men and women are probably attributed to fundamental differences in total adiposity, muscle mass, and fat distribution (i.e., visceral versus subcutaneous fat) [9].

It is well documented that excessive energy supply and subsequent overweight and/or obesity adversely affect insulin action [10]. On the other hand, it has been demonstrated that also fasting decreases insulin sensitivity [11].

However, the underlying mechanisms inducing insulin resistance in both conditions have not been completely 
elucidated. Based on existing studies, it appears that they are different, because the IR changes in obesity are associated with the increased plasma free fatty acid (FFA) levels, increased inflammatory cytokines, and excessive reactive oxygen species (ROS) production, while in fastinginduced IR exclusively an increase in FFA was observed [12].

An important factor positively affecting insulin sensitivity is physical activity. Both physically active individuals and athletes are characterized by higher insulin sensitivity and glucose effectiveness than sedentary controls [13].

However, it should be stressed that regular physical activity offers health benefits if it is accompanied by an adequate diet [14]. When the energy supply is insufficient or excessive in relation to energy expenditure, a number of metabolic disturbances appear, including altered insulin and other glucostatic hormones (e.g., cortisol and TSH) actions [15].

Metabolic effects of low energy availability as a consequence of dietary energy restriction and high energy expenditure have been thoroughly studied in females, since they cause many metabolic disturbances such as depressed ovarian hormone secretion, decreased bone mineral density, distorted lipoprotein profile, and endothelial dysfunction [16].

Data concerning effects of caloric restriction in young, healthy active males are limited. Hinton and Beck [17] have found that collegiate male athletes also are at risk of inadequate energy consumption. According to Pasiakos et al. [18] inadequate energy intake in both sexes has downregulated metabolic processes due to depressed synthesis of intracellular signaling proteins. Moreover, Loucks et al. [19] have emphasized that health risk factors of energy restriction are not limited to female subjects.

Moreover, most studies concerning disturbances in insulin action with respect to physical activity and/or dietary habits concern middle-aged and/or older individuals with obesity and type 2 diabetes [20,21].

Thus, this study was undertaken to evaluate metabolic profile and daily caloric intake in young, healthy active men with respect to calculated index of insulin resistance (HOMA-IR).

\section{Materials and Methods}

2.1. Subjects. A total of 87 physical education male students were enrolled in our study. Participants were recruited by advertisements in student dormitories and by word of mouth. They were healthy, nonsmokers, and not taking medication on a regular basis. All the participants signed informed consent and the study has been approved by local Ethics Commission.

2.2. Anthropometric Methods. Body composition was estimated using the bioelectrical impedance method and BC 418 MA equipment (Tanita Co., Japan). Inter- and intra-assay coefficients of variation for body fat measurements did not exceed $5 \%$.
2.3. Energy Intake. Participants were instructed to maintain their usual diet. Dietary intake was assessed for 4 days (two weekdays and weekend). Subjects provided 24-hour food records, which were next evaluated by an experienced interviewer using the Album of Photographs of Food Products and Meals. Nutritional data were analyzed using computer program Dieta 5.0. purchased in the National Food and Nutrition Institute in Warsaw [22]. Energy intake (EI) of each person was assessed individually, in relation to standards taking into account the body mass and physical activity.

2.4. Energy Expenditure. Activity energy expenditure (AEE) was evaluated using the Seven-Day Physical Activity Recall (SDPAR) questionnaire [23].

2.5. Biochemical Analyses. Fasting venous blood samples were collected into lithium heparin tubes using disposable syringes and needles under aseptic conditions. Blood was drawn between 7:30 and 9:00 a.m., centrifuged (15 min, $4000 \mathrm{rpm}, 4^{\circ} \mathrm{C}$ ), and stored at $-70^{\circ} \mathrm{C}$ until analysis. Blood glucose levels were determined by the oxidase method. Plasma triglycerides (TG), total cholesterol (TC), and highdensity lipoprotein cholesterol (HDL-C) were measured with colorimetric methods. All determinations were performed using Randox commercial kits (Randox Laboratories, UK). Inter- and intra-assay coefficients of variation for glucose, TG, TC, and HDL-C determination did not exceed 5\%. Lowdensity lipoprotein cholesterol (LDL-C) was calculated using Friedewald formula [24].

Plasma levels of insulin, cortisol, and TSH were determined by standard radioimmunoassay methods using BioSource commercial kits (Belgium). Inter- and intra-assay coefficients of variation for hormones did not exceed $7 \%$.

Insulin resistance was calculated by homeostasis assessment model (HOMA-IR) and calculated from fasting insulin and glucose concentration according to the formula: insulin $(\mu \mathrm{IU} / \mathrm{mL}) \times$ glucose $(\mathrm{mmol} / \mathrm{L}) / 22.5[25]$. The median value of HOMA-IR (1.344) was used to divide study population into Group A (above the median, $n=43$ ) and Group B (below the median, $n=44)$.

2.6. Statistical Analyses. Data distribution was assessed by the Shapiro-Wilk test. Data are expressed as means \pm SD and the level of significance for all statistical tests was set at $P<$ 0.05 . Student's $t$-test or the Mann-Whitney test was used for comparison between groups, for normally and not normally distributed variables, respectively. Pearson product moment and Spearman rank correlation coefficients were calculated to evaluate the associations between variables. Data analyses were performed using Statistica v.9 (StatSoft, USA).

\section{Results}

The anthropometric, dietary, and metabolic characteristics of all subjects are listed in Tables 1 and 2.

Tables 3 and 4 present data of subjects divided into Group A and Group B. As shown in Table 3 men from Group A did not differ significantly from men in Group B in body fat 
TABLE 1: Characteristics of the 87 subjects.

\begin{tabular}{lc}
\hline Variable & Mean \pm SD \\
\hline Age $(\mathrm{yr})$ & $19.8 \pm 0.8$ \\
Body mass $(\mathrm{kg})$ & $76.6 \pm 8.8$ \\
Body height $(\mathrm{cm})$ & $180.6 \pm 6.0$ \\
Fat $(\%)$ & $12.6 \pm 4.4$ \\
Fat $(\mathrm{kg})$ & $9.8 \pm 4.2$ \\
AEE (kcal/day) & $776.4 \pm 353.5$ \\
EI (kcal/day) & $2771.5 \pm 690.9$ \\
Protein (g) & $98.0 \pm 27.6$ \\
Protein $(\%$ E) & $14.5 \pm 2.6$ \\
Fat (g) & $114.7 \pm 34.8$ \\
Fat $(\%$ E) & $36.5 \pm 5.8$ \\
Carbohydrate $(\mathrm{g})$ & $355.4 \pm 100.7$ \\
Carbohydrate $(\% \mathrm{E})$ & $49.5 \pm 8.2$ \\
\hline
\end{tabular}

AEE: activity energy expenditure; EI: energy intake.

content. Furthermore, daily physical activity of participants expressed in $\mathrm{kcal} /$ day was similar.

However, in men with higher HOMA-IR values significantly lower daily energy intake was observed in comparison to their counterparts with lower HOMA-IR (by 13.6\%, $P<$ 0.01 ). There were no differences in the percentage of energy from proteins, fats, and carbohydrates between groups.

In Group A plasma glucose and insulin levels were higher than in Group B (by 11.8\% $(P<0.001)$ and 39.3\% $(P<0.001)$ for glucose and insulin, resp.) (Table 4). Likewise, plasma TG, TC, and HDL-C concentrations were significantly higher in men with HOMA-IR higher the median (by $22.2 \%, P<0.01$, by $6.4 \%, P<0.05$, and $13.3 \%, P<0.05$, resp.). However, plasma cortisol and TSH levels were similar in both groups.

Exclusively in men with higher HOMA-IR (Group A) a significant and positive correlation was noted between HOMA-IR and TC, LDL-C (Table 5).

\section{Discussion}

This study provided two important findings. First, we observed highly differentiated insulin resistance (estimated by HOMA-IR) in young lean men with similar body fat and activity level. Secondly, participants with higher HOMA-IR values were characterized by lower daily energy intake and less favorable lipoprotein profile.

However, from our data it is difficult to evaluate insulin resistance in participants of the study due to divergent results concerning HOMA-IR cutoffs. Conus et al. [26] have classified young women as insulin resistant based on a cut point of HOMA > 1.69, but Capasso et al. [27] have postulated HOMA-IR $\geq 2.5$ as the cutoff value to define insulin resistance.

On the other hand, mean HOMA-IR values in our participants (1.537) were higher than reported by others in young males (1.400-1.457), but close to that found in healthy middle-aged men (1.600) [28-30]. Thus, it could not be excluded that at least some of our participants were insulin resistant.
One of the important predictors of insulin sensitivity is caloric intake. Our results are in agreement with animal studies which have indicated elevated IR during caloric restriction [31].

The mechanism of this is not fully elucidated. However, it has been suggested that insulin resistance in response to energy deficiency is a survival strategy, which leads to increased fat oxidation in skeletal muscle and spares glucose for utilization by the brain $[32,33]$.

Additionally, it has been demonstrated that energy shortage brings about stimulation of catecholamine secretion adversely affecting insulin sensitivity $[34,35]$.

However, it should be noted that in our study difference in caloric intake between groups characterized by markedly different HOMA-IR was significant but relatively small. On the other hand, taking into account activity energy expenditure and subjects body mass, recommended caloric intake has to be closed to $3000 \mathrm{kcal} / \mathrm{day}$ [36]. Thus, subjects with lower HOMA-IR were close to recommended, but subjects with higher HOMA-IR were by $20 \%$ lower than recommended intake.

Previous studies have postulated that reduced insulin sensitivity is associated with higher fat mass, lower fat free mass, and greater central fat accumulation [37]. In our study no significant differences in total body fat were found between men who varied in HOMA-IR values. However, it could not be excluded that our participants differed in visceral fat markedly affecting insulin sensitivity [38].

It was found that insulin resistance is associated with increased cardiovascular risk [39]. Many studies have shown that impaired insulin action is accompanied by atherogenic lipid profile, that is, elevated plasma levels of TG and LDL-C and decreased HDL-C [40].

In the current study young, active men with higher HOMA-IR (Group A) showed significantly higher fasting triglycerides and total cholesterol in comparison to Group B, which should be regarded as an unfavorable change in terms of health.

Numerous data have demonstrated that circulating cortisol and TSH affect energy balance, lipoprotein profile, and insulin sensitivity [41, 42]. However, in our subjects plasma levels of both hormones did not differ irrespectively of caloric intake and HOMA-IR values.

This possibly suggests that insufficient energy intake first of all leads to an increase in circulating insulin and HOMA-IR values. It seems that these changes precede that in body fat content, cortisol, and TSH levels due to caloric restriction [43]. Moreover, it could not be excluded that insulin sensitivity is a very subtle indicator of energy balance in physically active young men.

In conclusion, we found that despite a normal body weight and increased physical activity, a subset of young men display unfavorable changes in insulin sensitivity and lipid profile, probably due to insufficient energy intake.

However, this study has several limitations and to confirm our results determination of basal metabolic rate and more precise determination of insulin sensitivity in young, active men are necessary. 
TABLE 2: Biochemical variables of the 87 subjects.

\begin{tabular}{lcc}
\hline Variable & Mean \pm SD & Reference values \\
\hline Glucose $(\mathrm{mmol} / \mathrm{L})$ & $4.8 \pm 0.6$ & $3.89-5.83$ \\
Insulin $(\mu \mathrm{IU} / \mathrm{mL})$ & $7.1 \pm 2.7$ & $1.0-25.0$ \\
$\mathrm{TG}(\mathrm{mmol} / \mathrm{L})$ & $0.81 \pm 0.4$ & $0.4-1.53$ \\
$\mathrm{TC}(\mathrm{mmol} / \mathrm{L})$ & $4.52 \pm 0.7$ & $<5.2$ \\
$\mathrm{HDL}-\mathrm{C}(\mathrm{mmol} / \mathrm{L})$ & $1.43 \pm 0.4$ & $0.89-2.5$ \\
$\mathrm{LDL}-\mathrm{C}(\mathrm{mmol} / \mathrm{L})$ & $2.68 \pm 0.8$ & $<3.5$ \\
Cortisol $(\mathrm{nmol} / \mathrm{L})$ & $374.9 \pm 148.0$ & $131-642(8-10 \mathrm{AM})$ \\
TSH $(\mu \mathrm{IU} / \mathrm{mL})$ & $2.1 \pm 1.0$ & $0.2-4.1$ \\
HOMA-IR & $1.537 \pm 0.736$ & - \\
\hline
\end{tabular}

TABLE 3: Characteristics of the subjects categorized by HOMA-IR median value (means \pm SD).

\begin{tabular}{lcc}
\hline Variable & Group A $(n=43)>$ median HOMA-IR & Group B $(n=44) \leq$ median HOMA-IR \\
\hline Age $(\mathrm{yr})$ & $19.7 \pm 0.8$ & $19.9 \pm 0.8$ \\
Body mass $(\mathrm{kg})$ & $76.4 \pm 8.4$ & $76.4 \pm 9.2$ \\
Body height $(\mathrm{cm})$ & $180.7 \pm 6.0$ & $180.5 \pm 6.1$ \\
Fat $(\%)$ & $13.3 \pm 4.6$ & $11.9 \pm 4.2$ \\
Fat $(\mathrm{kg})$ & $10.4 \pm 4.3$ & $9.3 \pm 4.1$ \\
AEE (kcal/day) & $751.1 \pm 362.9$ & $801.1 \pm 346.6$ \\
EI (kcal/day) & $2569.4 \pm 607.8^{* *}$ & $2973.5 \pm 716.9$ \\
Protein (g) & $92.0 \pm 22.3$ & $104.0 \pm 31.2$ \\
Protein (\%) & $14.7 \pm 2.4$ & $14.4 \pm 2.8$ \\
Fat (g) & $106.9 \pm 31.4^{*}$ & $122.6 \pm 36.6$ \\
Fat (\%) & $36.5 \pm 4.5$ & $36.5 \pm 6.9$ \\
Carbohydrate $(\mathrm{g})$ & $327.1 \pm 81.2^{* *}$ & $383.6 \pm 111.0$ \\
Carbohydrate $(\%)$ & $48.8 \pm 5.2$ & $50.3 \pm 10.4$
\end{tabular}

AEE: activity energy expenditure; EI: energy intake; ${ }^{* *} P<0.01,{ }^{*} P<0.05$ significantly different versus Group B.

TABLE 4: Biochemical variables in subjects differed by HOMA-IR (means \pm SD).

\begin{tabular}{lcc}
\hline Variable & Group A $(n=43)>$ median HOMA-IR & Group B $(n=44) \leq$ median HOMA-IR \\
\hline Glucose $(\mathrm{mmol} / \mathrm{L})$ & $5.1 \pm 0.5^{* * *}$ & $4.5 \pm 0.4$ \\
Insulin $(\mu \mathrm{IU} / \mathrm{mL})$ & $8.9 \pm 2.8^{* * *}$ & $5.4 \pm 0.8$ \\
HOMA-IR & $2.020 \pm 0.781^{* * *}$ & $1.065 \pm 0.163$ \\
TG $(\mathrm{mmol} / \mathrm{L})$ & $0.9 \pm 0.4^{* *}$ & $0.7 \pm 0.3$ \\
TC $(\mathrm{mmol} / \mathrm{L})$ & $4.7 \pm 0.8^{*}$ & $4.4 \pm 0.6$ \\
HDL-C $(\mathrm{mmol} / \mathrm{L})$ & $1.5 \pm 0.4^{*}$ & $1.3 \pm 0.3$ \\
LDL-C $(\mathrm{mmol} / \mathrm{L})$ & $2.7 \pm 0.9$ & $2.6 \pm 0.6$ \\
Cortisol $(\mathrm{nmol} / \mathrm{L})$ & $391.1 \pm 142.4$ & $359.2 \pm 153.2$ \\
TSH $(\mu \mathrm{IU} / \mathrm{mL})$ & $2.1 \pm 1.0$ & $2.0 \pm 1.0$ \\
\hline
\end{tabular}

${ }^{* * *} P<0.001 ;{ }^{* *} P<0.01 ;{ }^{*} P<0.05$ significantly different versus Group B.

TABLE 5: Correlation coefficients between HOMA-IR and biochemical variables in participants.

\begin{tabular}{lcc}
\hline Variable & Group A $(n=43)>$ median HOMA-IR & Group B $(n=44) \leq$ median HOMA-IR \\
\hline TG $(\mathrm{mmol} / \mathrm{L})$ & 0.12 & 0.08 \\
TC $(\mathrm{mmol} / \mathrm{L})$ & $0.42^{*}$ & -0.03 \\
HDL-C $(\mathrm{mmol} / \mathrm{L})$ & -0.17 & 0.02 \\
LDL-C $(\mathrm{mmol} / \mathrm{L})$ & $0.46^{*}$ & -0.18 \\
Cortisol $(\mathrm{nmol} / \mathrm{L})$ & 0.10 & -0.17 \\
TSH $(\mu \mathrm{IU} / \mathrm{mL})$ & -0.21 & 0.22 \\
\hline
\end{tabular}

\footnotetext{
${ }^{*} P<0.05$.
} 


\section{Conflict of Interests}

The authors declare that they have no conflict of interests.

\section{Acknowledgment}

This work was supported by grants from the Józef Pilsudski University of Physical Education in Warsaw, DS.-132 and DS.147.

\section{References}

[1] A. Lancha, G. Frühbeck, and J. Gómez-Ambrosi, "Peripheral signalling involved in energy homeostasis control," Nutrition Research Reviews, vol. 25, no. 2, pp. 223-248, 2012.

[2] D. P. Begg and S. C. Woods, "Interactions between the central nervous system and pancreatic islet secretions: a historical perspective," Advances in Physiology Education, vol. 37, no. 1, pp. 53-60, 2013.

[3] F. Magkos, X. Wang, and B. Mittendorfer, "Metabolic actions of insulin in men and women," Nutrition, vol. 26, no. 7-8, pp. 686693, 2010.

[4] G. Bano, "Glucose homeostasis, obesity and diabetes," Best Practice \& Research Clinical Obstetrics \& Gynaecology, vol. 27, no. 5, pp. 715-726, 2013.

[5] E. Ginter and V. Simko, "Diabetes type 2 pandemic in 21st century," Advances in Experimental Medicine and Biology, vol. 771, pp. 42-50, 2012.

[6] C. Voulgari, N. Tentolouris, P. Dilaveris, D. Tousoulis, N. Katsilambros, and C. Stefanadis, "Increased heart failure risk in normal-weight people with metabolic syndrome compared with metabolically healthy obese individuals," Journal of the American College of Cardiology, vol. 58, no. 13, pp. 1343-1350, 2011.

[7] J. M. Lee, M. J. Okumura, M. M. Davis, W. H. Herman, and J. G. Gurney, "Prevalence and determinants of insulin resistance among U.S. adolescents: a population-based study," Diabetes Care, vol. 29, no. 11, pp. 2427-2432, 2006.

[8] A. S. Ryan, "Insulin resistance with aging: effects of diet and exercise," Sports Medicine, vol. 30, no. 5, pp. 327-346, 2000.

[9] C. Rattarasarn, R. Leelawattana, S. Soonthornpun, W. Setasuban, and A. Thamprasit, "Gender differences of regional abdominal fat distribution and their relationships with insulin sensitivity in healthy and glucose-intolerant Thais," Journal of Clinical Endocrinology and Metabolism, vol. 89, no. 12, pp. 62666270, 2004.

[10] S. H. Kim, F. Abbasi, and G. M. Reaven, "Impact of degree of obesity on surrogate estimates of insulin resistance," Diabetes Care, vol. 27, no. 8, pp. 1998-2002, 2004.

[11] B. C. Bergman, M.-A. Cornier, T. J. Horton, and D. H. Bessesen, "Effects of fasting on insulin action and glucose kinetics in lean and obese men and women," American Journal of Physiology Endocrinology and Metabolism, vol. 293, no. 4, pp. E1103-E1111, 2007.

[12] S. N. van der Crabben, G. Allick, M. T. Ackermans, E. Endert, J. A. Romijn, and H. P. Sauerwein, "Prolonged fasting induces peripheral insulin resistance, which is not ameliorated by highdose salicylate," The Journal of Clinical Endocrinology and Metabolism, vol. 93, no. 2, pp. 638-641, 2008.

[13] E. J. Mayer-Davis, R. D’Agostino, A. J. Karter et al., "Intensity and amount of physical activity in relation to insulin sensitivity,"
The Journal of the American Medical Association, vol. 279, no. 9, pp. 669-674, 1998.

[14] J. Caro, I. Navarro, P. Romero et al., "Metabolic effects of regular physical exercise in healthy population," EndocrinologíaY Nutrición, vol. 60, no. 4, pp. 167-172, 2013.

[15] G. Soleimany, H. Dadgostar, S. Lotfian et al., "Bone mineral changes and cardiovascular effects among female athletes with chronic menstrual dysfunction," Asian Journal of Sports Medicine, vol. 3, no. 1, pp. 53-58, 2012.

[16] N. Pollock, C. Grogan, M. Perry et al., "Bone-mineral density and other features of the female athlete triad in elite endurance runners: a longitudinal and cross-sectional observational study," International Journal of Sport Nutrition and Exercise Metabolism, vol. 20, no. 5, pp. 418-426, 2010.

[17] P. S. Hinton and N. C. Beck, "Nutrient intakes of men and women collegiate athletes with disordered eating," Journal of Sports Science and Medicine, vol. 4, pp. 253-262, 2005.

[18] S. M. Pasiakos, L. M. Vislocky, J. W. Carbone et al., "Acute energy deprivation affects skeletal muscle protein synthesis and associated intracellular signaling proteins in physically active adults," Journal of Nutrition, vol. 140, no. 4, pp. 745-751, 2010.

[19] A. B. Loucks, B. Kiens, and H. H. Wright, "Energy availability in athletes," Journal of Sports Sciences, vol. 29, no. 1, pp. S7-S15, 2011.

[20] B. Moreno and F. Casanueva, "Identification, diagnosis and control of patients with abdominal obesity and cardiovascular and metabolic risk factors," Medicina Clinica, vol. 128, no. 11, pp. 429-437, 2007.

[21] H. D. Do, V. Lohsoonthorn, W. Jiamjarasrangsi, S. Lertmaharit, and M. A. Williams, "Prevalence of insulin resistance and its relationship with cardiovascular disease risk factors among Thai adults over 35 years old," Diabetes Research and Clinical Practice, vol. 89, no. 3, pp. 303-308, 2010.

[22] L. Szponar, K. Wolnicka, and E. Rychlik, Album of Photographs of Food Products and Dishes, National Food and Nutrition Institute, Warsaw, Poland, 2000.

[23] J. F. Sallis, "Seven-days physical activity recall," Medicine and Science in Sports and Exercise, vol. 22, pp. 704-712, 1990.

[24] W. T. Friedewald, R. I. Levy, and D. S. Fredrickson, "Estimation of the concentration of low-density lipoprotein cholesterol in plasma, without use of the preparative ultracentrifuge," Clinical Chemistry, vol. 18, no. 6, pp. 499-502, 1972.

[25] D. R. Matthews, J. P. Hosker, and A. S. Rudenski, "Homeostasis Model Assessment: insulin resistance and $\beta$-cell function from fasting plasma glucose and insulin concentrations in man," Diabetologia, vol. 28, no. 7, pp. 412-419, 1985

[26] F. Conus, D. B. Allison, R. Rabasa-Lhoret et al., "Metabolic and behavioral characteristics of metabolically obese but normalweight women," The Journal of Clinical Endocrinology and Metabolism, vol. 89, no. 10, pp. 5013-5020, 2004.

[27] I. Capasso, E. Esposito, F. Pentimalli et al., "Homeostasis Model Assessment to detect insulin resistance and identify patients at high risk of breast cancer development: national cancer institute of Naples experience," Journal of Experimental \& Clinical Cancer Research, vol. 32, no. 1, p. 14, 2013.

[28] S. Lim, K. S. Park, M. S. Kim, B. Y. Cho, and H. K. Lee, "Relationship between various surrogate indices of insulin resistance and mitochondrial DNA content in the peripheral blood of 18 healthy volunteers," Mitochondrion, vol. 1, no. 1, pp. 71-77, 2001. 
[29] K. Niakaris, F. Magkos, N. Geladas, and L. S. Sidossis, "Insulin sensitivity derived from oral glucose tolerance testing in athletes: disagreement between available indices," Journal of Sports Sciences, vol. 23, no. 10, pp. 1065-1073, 2005.

[30] E. Bonora, S. Kiechl, J. Willeit et al., "Insulin resistance as estimated by Homeostasis Model Assessment predicts incident symptomatic cardiovascular disease in caucasian subjects from the general population: The Bruneck Study," Diabetes Care, vol. 30, no. 2, pp. 318-324, 2007.

[31] V. J. B. Matrins, T. M. M. Toledo Florêncio, L. P. Grillo et al., "Long-lasting effects of undernutrition," International Journal of Environmental Research and Public Health, vol. 8, no. 6, pp. 18171846, 2011.

[32] J. Hoeks, N. A. van Herpen, M. Mensink et al., "Prolonged fasting identifies skeletal muscle mitochondrial dysfunction as consequence rather than cause of human insulin resistance," Diabetes, vol. 59, no. 9, pp. 2117-2125, 2010.

[33] M. H. Vendelbo, B. F. F. Clasen, J. T. Treebak et al., "Insulin resistance after a 72-h fast is associated with impaired AS160 phosphorylation and accumulation of lipid and glycogen in human skeletal muscle," American Journal of Physiology Endocrinology and Metabolism, vol. 302, no. 2, pp. E190-E200, 2012.

[34] N. Khoury and J. B. McGill, "Reduction in insulin sensitivity following administration of the clinically used low-dose pressor, norepinephrine," Diabetes/Metabolism Research and Reviews, vol. 27, no. 6, pp. 604-608, 2011.

[35] S. Lindmark, U. Wiklund, P. Bjerle, and J. W. Eriksson, "Does the autonomic nervous system play a role in the development of insulin resistance? A study on heart rate variability in firstdegree relatives of Type 2 diabetes patients and control subjects," Diabetic Medicine, vol. 20, no. 5, pp. 399-405, 2003.

[36] M. Jarosz M and B. Bułhak-Jachymczyk, Normy ŻywIenIa CzłowIeka. Podstawy PrewencjI OtyłoścI I Chorób NIezakaźnych, PZWL, Warsaw, Poland, 2008.

[37] W. K. Wedin, L. Diaz-Gimenez, and A. J. Convit, "Prediction of insulin resistance with anthropometric measures: lessons from a large adolescent population," Diabetes, Metabolic Syndrome and Obesity, vol. 5, pp. 219-225, 2012.

[38] A. M. Sironi, R. Petz, D. de Marchi et al., "Impact of increased visceral and cardiac fat on cardiometabolic risk and disease," Diabetic Medicine, vol. 29, no. 5, pp. 622-627, 2012.

[39] S. M. Haffner, L. Mykkänen, A. Festa, J. P. Burke, and M. P. Stern, "Insulin-resistant prediabetic subjects have more atherogenic risk factors than insulin-sensitive prediabetic subjects: implications for preventing coronary heart disease during the prediabetic state," Circulation, vol. 101, no. 9, pp. 975-980, 2000.

[40] H. N. Ginsberg, Y.-L. Zhang, and A. Hernandez-Ono, "Metabolic syndrome: focus on dyslipidemia," Obesity, vol. 14, no. 2, pp. 41S-49S, 2006.

[41] L. P. Klieverik, S. F. Janssen, A. van Riel et al., "Thyroid hormone modulates glucose production via a sympathetic pathway from the hypothalamic paraventricular nucleus to the liver," Proceedings of the National Academy of Sciences of the United States of America, vol. 106, no. 14, 2009.

[42] I. Cusin, J. Rouru, and F. Rohner-Jeanrenaud, "Intracerebroventricular glucocorticoid infusion in normal rats: induction of parasympathetic-mediated obesity and insulin resistance," Obesity Research, vol. 9, no. 7, pp. 401-406, 2001.

[43] P. J. Havel, "Peripheral signals conveying metabolic information to the brain: short-term and long-term regulation of food intake and energy homeostasis," Experimental Biology and Medicine, vol. 226, no. 11, pp. 963-977, 2001. 


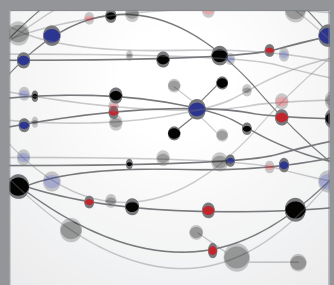

The Scientific World Journal
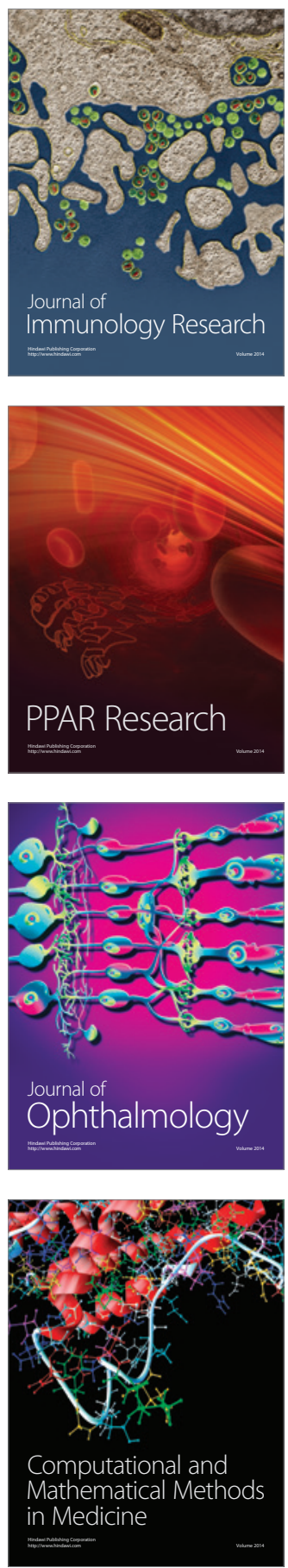

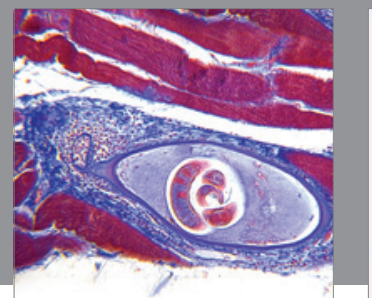

Gastroenterology

Research and Practice
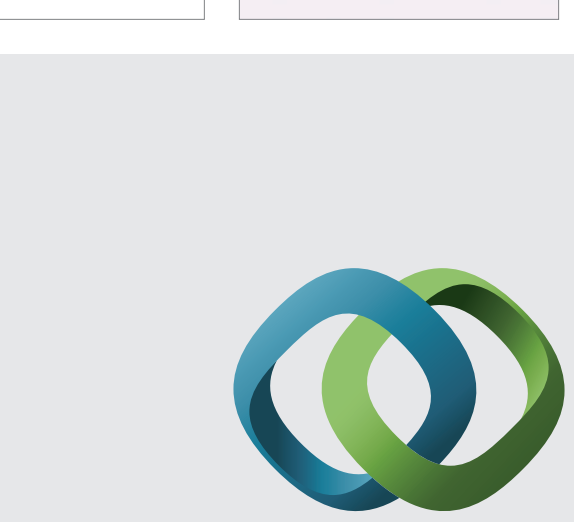

\section{Hindawi}

Submit your manuscripts at

http://www.hindawi.com
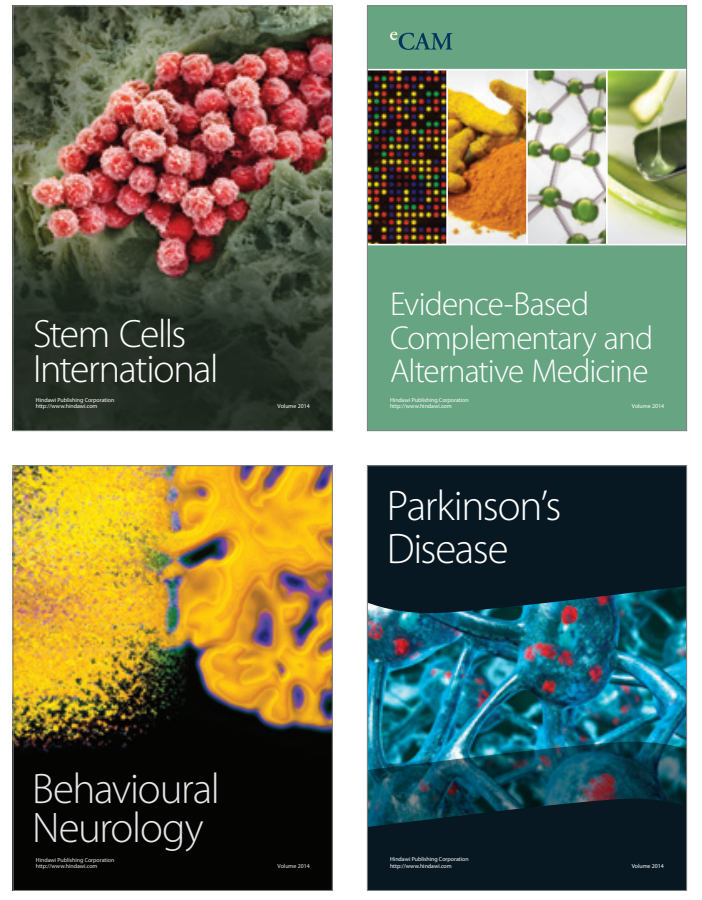
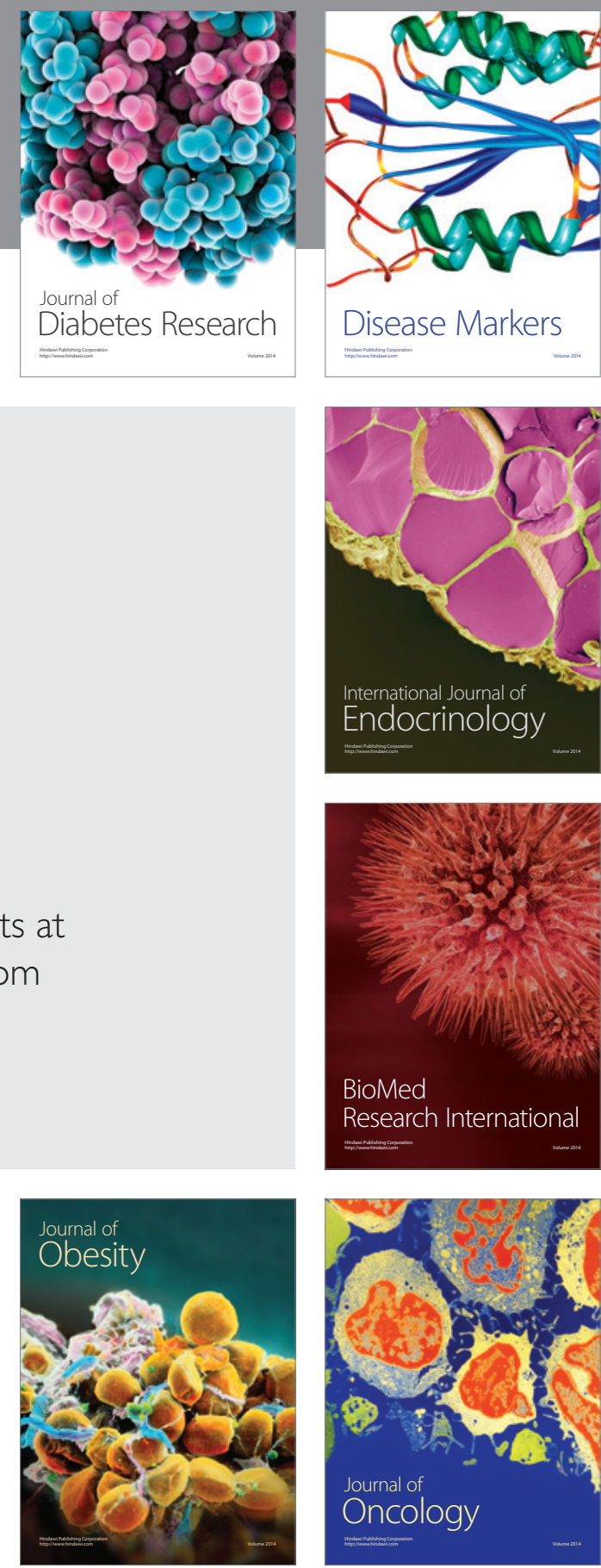

Disease Markers
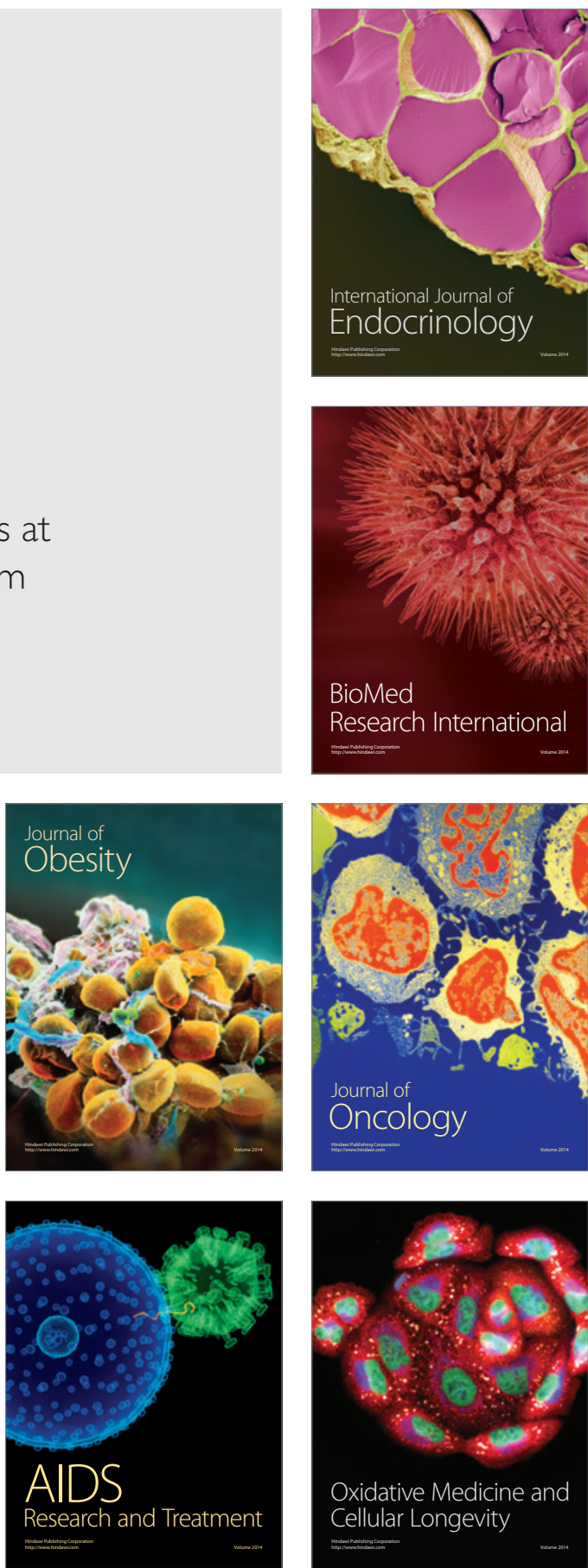